\title{
Hydropower dams threaten freshwater Chilean fish species: What dams and what species?
}

\author{
Anita Laborde ${ }^{1,}$, Evelyn Habit ${ }^{2}$, and Oscar Link $^{2}$ \\ ${ }^{1}$ University of Concepción, Aquatic System Department, 4030000 Edmundo Larenas s/n, Chile \\ ${ }^{2}$ University of Concepción, Civil Engineering Department, 4030000 Edmundo Larenas s/n, Chile
}

\begin{abstract}
Hydropower is experiencing a development boom worldwide. However, at the same time, challenge sustainability, mainly due to synergistic effects of several projects in the species distribution area. What and how hydroelectric projects will affect species, depends on a number of attributes. We analysed Chilean freshwater species distributed over 10 major basins of Central Chile threaten by 1124 plants $(12,338 \mathrm{GW})$ planned in a hotspot of biodiversity. The exposure of the species to the planned hydropower projects was analyzed at the scale of species and as an assemblage. The hazardousness was evaluated by type, according to characteristics of planned hydropower plant: size, dam height and turbine type. Finally, considering species and assemblage exposition the most threaten genera were defined. Project analysed compile $45 \%$ of the exploitable potential, with a total of $198(75.5 \%)$ project with capacities < 20MW, and $280(88.1 \%)$ with low head dams $(<20 \mathrm{~m}) .22 .6 \%$ of the species are not exposed to planned plants, $54.8 \%$ are exposed to a small number of plants $(<5)$, and $22.6 \%$ are frequently exposed to plants $(>60)$. The latter species pertain to genera Trichomycterus, Percilia, and Diplomystes, defining a critical fish assemblage that facilitates the management of an important part of the cases (40.4\%) through mitigation technologies.
\end{abstract}

\section{Introduction}

Increasing energy demand due to growing population and industrialization is exerting pressures on ecosystems worldwide, especially on those having available potential pertaining to the non-conventional renewable energies NCRE (Latrubesse et al. 2017). In this context, hydropower presents comparative advantages with respect to other NCREs (i.e. wind, solar, wave, tides, geothermal, a.o.) such as large exploitable potential, mature technology, negligible emission of greenhouse gases, and economically competitive low operation costs (Zhou et al., 2015). Hydropower is the dominant renewable energy source. However, at the same time, associated longitudinal fragmentation of the physical habitat negatively impacts the conservation status of freshwater species, challenging sustainability. Connectivity between habitats can be critical to ensuring the long-term persistence and success of fish populations (Fullerton et al., 2010). Lack of access to different habitats, can

\footnotetext{
* Corresponding author: a.labordegarcia@gmail.com
} 
ultimately lead to a population decline, and a loss of biodiversity (Franklin and Bartels, 2012). Nevertheless, not all planned SHP will affect freshwater fish species. What projects will potentially affect species, depend on a number of attributes such as location and size, while what species are potentially vulnerable to hydropower projects depends on a number of species specific attributes such as distribution and conservation status. Additionally, mitigation technologies to reduce the impact of hydropower projects on freshwater fish species are available (Noatch and Suski, 2012; Noonan et al., 2011; Kemp, 2016).

\section{Study area}

The study area corresponds to the 10 major basins of Central Chile (between $32^{\circ}$ and $41^{\circ}$ Lat. S) form Maipo to Bueno rivers. About $90 \%$ of the area is drained by river flowing mainly from East to West with a total length of about $200-400 \mathrm{~km}$, Strahler's orders up to eight, an annual mean discharges at the mouth between 100 and $1000 \mathrm{~m}^{3} / \mathrm{s}$. All fluvial systems follow the same pattern, flowing form the Andean glaciers (with slopes about 5$10 \%$ ) through the Central Valley and Coastal Chain of Hills (with slopes about 0.5/1000) into the Pacific Ocean (Link and Habit, 2015)

The drainage networks and their properties, such as river length, Strahler's order, elevation, were defined using GIS software Arc GIS 10.3. from SRTM satellite images.

\subsection{Freshwater fish species}

The study area hosts 31 species (65.9\%) of the 47 Chilean freshwater species (Habit et al., 2006). These 31 species, are grouped in 7 families, 16 genera, 14 Teleosts and 2 Agnatha (lampreys). Of all the species present in the study area, $35.4 \%$ are smaller than $15 \mathrm{~cm}$ total length (TL) when adults and only $19.4 \%$ reach adult sizes $>25 \mathrm{~cm}$ TL. The most abundant groups are the Siluriforms ( 9 species) and Osmeriforms ( 7 species). Other groups represented in the study area are Characiforms (4 species), Atheriniforms (4 species), Perciforms (4 species), Petromyzontiforms (2 species) and Mugiliforms (1 species) (Habit et al., 2006). In this region, $74.2 \%$ of the fish species are endemic, $38.7 \%$ and $48.3 \%$ are classified as Endangered and Vulnerable, respectively.

\subsection{Planned hydropower plants}

Location and size of planned hydropower projects was obtained from Ministry of Energy (2015). The exploitable hydropower in the study area is $12,338 \mathrm{GW}$ distributed in 1124 sites, with a total of $587(52,2 \%)$ projects with capacities < $3 \mathrm{MW}, 329(35,5 \%)$ with capacities between 3 and $20 \mathrm{MW}$, and $138(12,3 \%)$ projects with more than $20 \mathrm{MW} .24$ $(1,8 \%)$ of these projects are located in the Coastal plain, $127(17,5 \%)$ in the Central Valley, and $903(80,3 \%)$ in the Andean range. Figure 1 shows the planned plants on the morphological units of the study area, classified by size, and available fish sampling sites. 


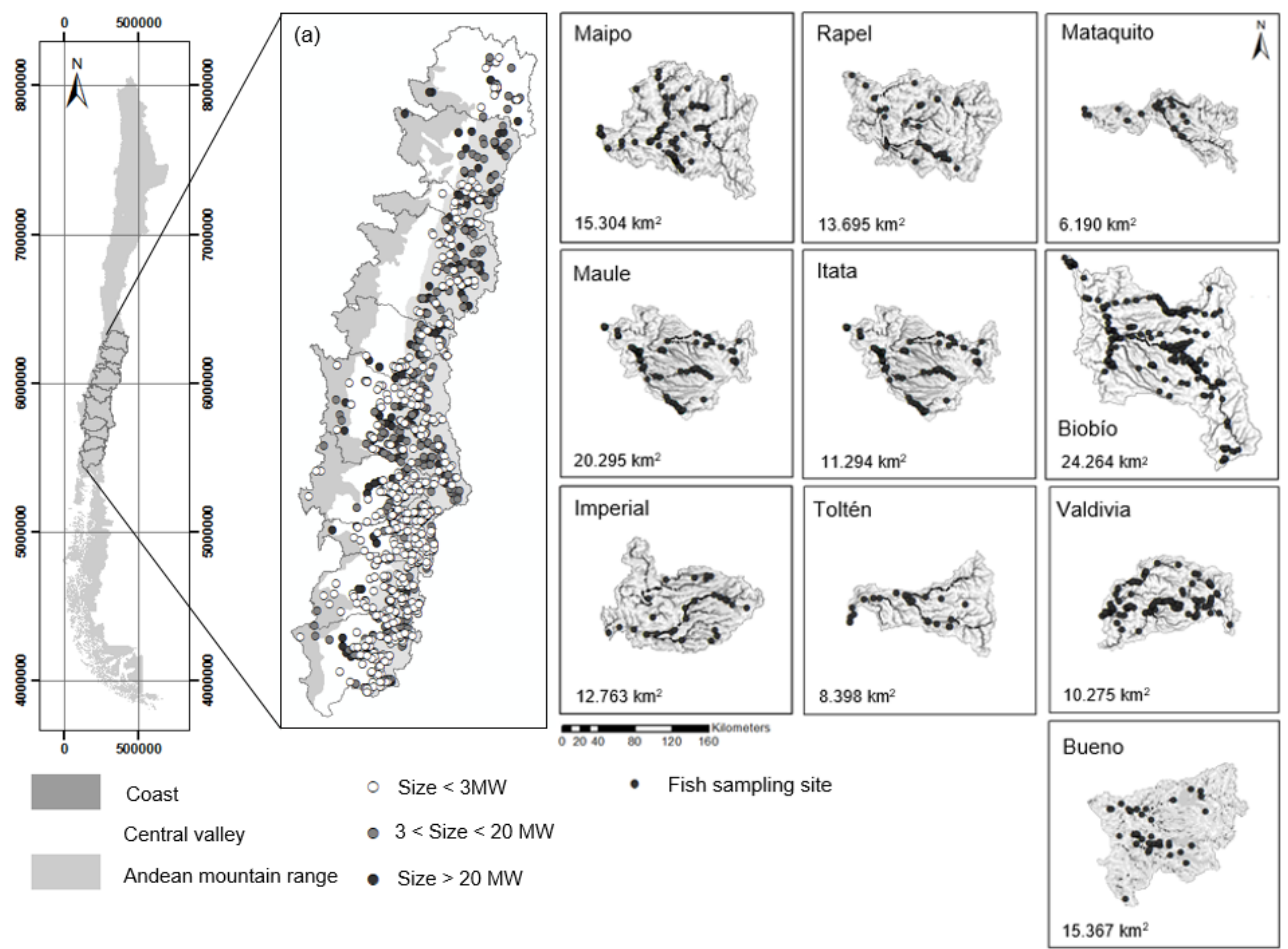

Fig. 1. Study area distinguishing the morphological units, planned hydropower plants classified by size and available fish sampling sites.

\subsection{Methodology}

Historical data of presence/absence included over 3,500 records in the study area and was used to estimate species distribution and species richness (see Figure 1).

Species distribution was determined at the river reach. Interpolation of the information between sampling sites along a river reach was performed considering fish habitat use of each species. Extrapolation of the information from the sampling sites to downstream was based on the stream order and elevation, migratory behaviour and dispersion abilities of the fish species. The longitude of river reaches over which species distribute was computed as the sum of the reach lengths where the species were present.

Species richness was computed as the sum of the species present in a reach.

As most planned projects are still undefined, based on available information for the planned hydropower projects dam height and turbine type were estimated.

Dam height was estimated based on plant size expressed as capacity, $\mathrm{P}$, and the distance between the intake and restitution, L, and two classes were mainly distinguished according to the relevance for habitat connectivity. Dam height, $\mathrm{H}$, was classified ass less than $20 \mathrm{~m}$. $(\mathrm{H}<20 \mathrm{~m})$, greater than $20 \mathrm{~m}$. $(\mathrm{H}>20 \mathrm{~m})$, unknown (not clear), no information (one of the variables in was not available). $\mathrm{H}<20 \mathrm{~m}$. if: (a) $\mathrm{P}<20 \mathrm{MW}$, (b) $\mathrm{P}<50 \mathrm{MW}$ and $\mathrm{L}>500$ m. While $\mathrm{H}>20 \mathrm{~m}$. if: (a) $\mathrm{L} \leq 200 \mathrm{~m}$ and $\mathrm{P}>50 \mathrm{MW}$, (b) $500 \mathrm{~m} \leq \mathrm{L} \leq 15000 \mathrm{~m}$ and $\mathrm{P} \geq$ $150 \mathrm{MW}$.

Turbine type was defined based on head and flow in each hydropower plant considering the design curves for pelton, francis and kaplan turbines. 
Planned hydropower projects that overlap river reaches with species distribution were considered.

The exposure of the species to the planned hydropower projects was analyzed at the scale of species and as an assemblage, by the sum of the number of planned plants where the species or the assemblage is present. Assemblage was defined as the group of species that inhabit the same stretch of the river.

In addition, the species exposition for vulnerable and endangered was defined.

The hazardousness was evaluated by type, according to characteristics of planned hydropower plant: size, dam height and turbine type.

In the species exposition analysis, the ANOSIM test on a Bray-Curtis resemblance matrix (ANOSIM; Primer v.7, Clarke and Gorley 2014) was used to test the differences in species composition and frequency of occurrence (presence/absence data) within exposition type.

Finally, considering species and assemblage exposition the most threaten genera were defined. For them, the hazardousness was also evaluated according to characteristics of planned hydropower plants.

\section{Results}

\subsection{Characterization of the analysed planned hydropower plants}

The exploitable hydropower in the analysed planned plants is 5,630 GW distributed in 262 sites, with a total of $87(33.2 \%)$ project with capacities < 3MW, $111(42.4 \%)$ with capacities between 3 and $20 \mathrm{MW}$, and 64 (24.4\%) projects with more than $20 \mathrm{MW} .4$ $(1.5 \%)$ of these projects are located in the Coastal plain, 75 (29\%) in the Central Valley, and $183(70 \%)$ in the Andean range.

\subsection{Exposition as species scale}

Of the 31 species present in the study area, 6 species (19.3\%), namely Diplomystes chilensis, Brachygalaxias gothei, Mugil cephalus, Aplochiton marinus, Odontesthes brevianalis and Odontesthes itatanum are distributed in reaches without planned plants. 17 species (54.8\%) overlap with at least 4 planned plants, and the 8 most widely distributed species, namely Trichomycterus areolatus, Basilichthys microlepidotus, Percichthys trucha, Percilia gillissi, Galaxias maculatus, Percilia irwini, Diplomystes nahuelbutaensis, Diplomystes incognitus overlap with more than 45 planned plants. Among this group Diplomystes incognitus, Diplomystes nahuelbutaensis, Percilia irwini are endemic to the study area.

\subsection{Exposition as assemblage scale}

Because species are generally not exposed to a hydropower project alone, assemblages exposition was also analysed. Eleven assemblages are exposed by at least five projects. From them, three are composed of one species, five of two species, one of three, four and seven species (see Table 1). 
Table 1. Exposed assemblages and river basins.

\begin{tabular}{|c|c|c|c|}
\hline $\begin{array}{l}\text { Species } \\
\text { richness }\end{array}$ & Assemblage & $\begin{array}{l}\mathrm{N}^{\circ} \text { of } \\
\text { planned } \\
\text { plants }\end{array}$ & $\begin{array}{l}\text { River } \\
\text { basins }\end{array}$ \\
\hline 1 & Trichomycterus areolatus & 27 & $\begin{array}{l}\text { Maipo, Maule, } \\
\text { Itata, Biobío, } \\
\text { Imperial, Bueno }\end{array}$ \\
\hline 1 & Diplomystes incognitus & 12 & Mataquito, Maule \\
\hline 1 & Galaxias maculatus & 6 & Toltén \\
\hline 2 & Trichomycterus areolatus, Percilia irwini & 16 & Biobío \\
\hline 2 & $\begin{array}{l}\text { Trichomycterus areolatus, Diplomystes } \\
\text { incognitus }\end{array}$ & 13 & $\begin{array}{l}\text { Rapel, Mataquito, } \\
\text { Maule, Itata }\end{array}$ \\
\hline 2 & Percilia gillisi, Diplomystes incognitus & 8 & Maule, Itata \\
\hline 2 & $\begin{array}{c}\text { Diplomystes nahuelbutaensis, Percichthys } \\
\text { melanops }\end{array}$ & 7 & Biobío \\
\hline 2 & $\begin{array}{c}\text { Trichomycterus areolatus, Diplomystes } \\
\text { nahuelbutaensis }\end{array}$ & 5 & Biobío \\
\hline 3 & $\begin{array}{c}\text { Trichomycterus areolatus, Percilia gillisi, } \\
\text { Diplomystes incognitus }\end{array}$ & 11 & $\begin{array}{l}\text { Mataquito, } \\
\text { Maule, Itata }\end{array}$ \\
\hline 4 & $\begin{array}{c}\text { Nematogenys inermis, Trichomycterus } \\
\text { areolatus, Percilia irwini, Diplomystes } \\
\text { nahuelbutaensis }\end{array}$ & 5 & Biobío \\
\hline 7 & $\begin{array}{c}\text { Cheirodon galusdae; Bullockia } \\
\text { maldonadoi; Trichomycterus areolatus; } \\
\text { Diplomystes nahuelbutaensis; Basilichthys } \\
\text { microlepidotus; Percilia irwini; Percichthys } \\
\text { trucha }\end{array}$ & 10 & Biobío \\
\hline
\end{tabular}

Table 3 shows basins with greater specific richness have assemblages with a greater number of species. Predictably, when assemblages exposition is analyzed, threatened species are similar to the results of species exposition analysis.

\subsubsection{Setting priorities}

The most threatened genera are Trichomycterus, Percilia and Diplomystes, affected by 106 projects, concentrating the threat of $40.4 \%$ of the projects analyzed, alone or a combination of them without presence of other species (see Figure 2). 


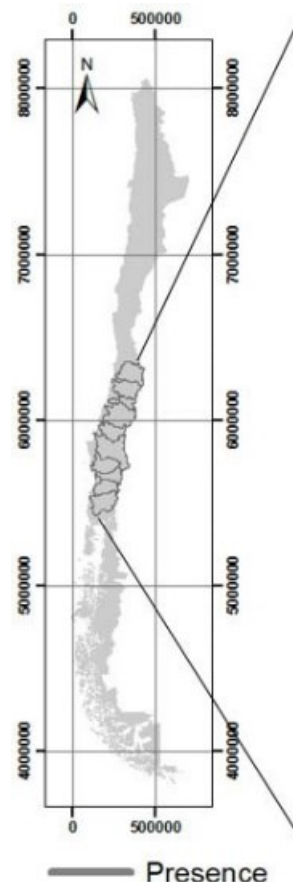

Presence

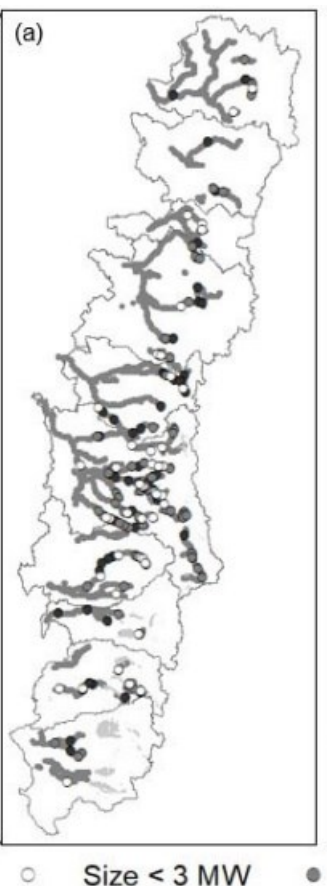

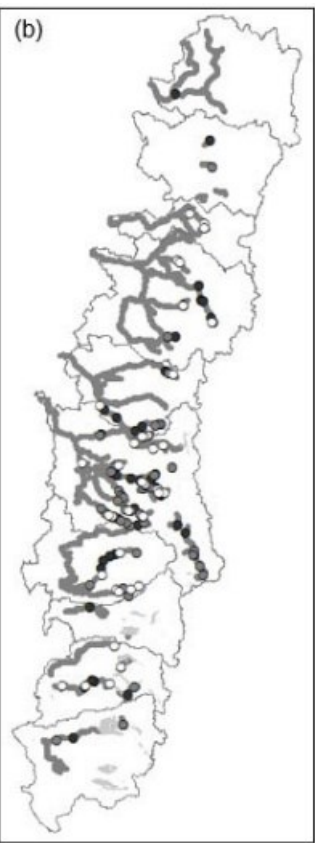

$3<$ Size $<20 \mathrm{MW}$

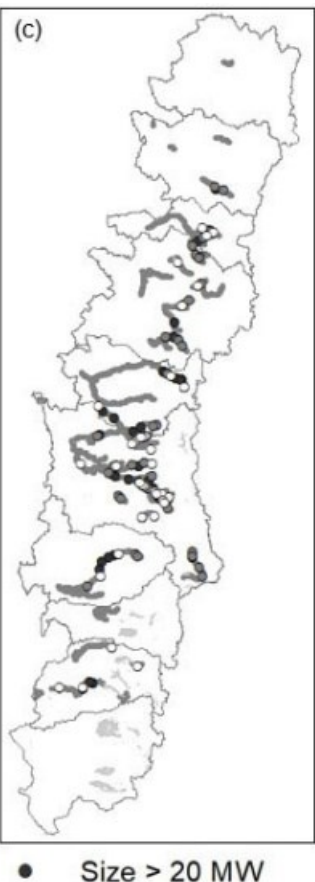

Fig. 2. Presence of genera (a) Trichomycterus, (b) Percilia, and (c) Diplomystes, and threatening planned plants classified by size.

\section{Conclusion}

Chile has a huge hydroelectric potential that is expected to be exploited in the coming years due to the 2050 Energy policy. This potential can make a significant contribution to future energy needs. River reaches with information about species distribution were analysed. A total of 262 projected plants that compile $45 \%$ of the exploitable potential were analysed. $69.8 \%$ of these plants are located in the Andean range, $28.6 \%$ in the Central Valley, and $1.5 \%$ in the Coastal plain. $58.7 \%$ is located in reaches with low Strahler order $(\leq 3) .75 .5 \%$ have installed capacities less than $20 \mathrm{MW}, 88.1 \%$ consider low height dams $(<20 \mathrm{~m})$, and $4.6 \%, 64.7 \%$ and $18.6 \%$ consider Pelton, Francis, and Kaplan turbines respectively.

Exposition to plants by species and groups was analysed. As species, T. areolatus, B. microlepidotus, P. trucha, P. gillissi, G. maculatus, P. irwini, D. nahuelbutaensis, D. incognitus concentrate the threat (with more than 45 planned plant exposition each of them). Because projects generally do not threaten only one specie, we analyze threatened groups. The genera Trichomycterus, Percilia and Diplomystes, affected by 106 projects, concentrating the threat of $40.4 \%$ of the projects analyzed. The concentration of the threat allows us to think of a single solution for the three genera.

\section{References}

1. K. Clarke, R. Gorley, P. Somerfield, R. Warwick, PRIMER-e Ltd: Plymouth Marine Laboratory, 262pp, (2014) 
2. P. Franklin, B. Bartles, Aquatic Conservation: Marine and Freshwater Ecosystems, 22(4), 489-497, (2012)

3. A. Fullerton, K. Burnett, E. Steel, R. Flitcoft, G. Pess, B. Feist, C. Torgersen, D. Miller, N. Sanderson, Freshwater Biology, 55, 2215-2237, (2010)

4. E. Habit, B., Dyer, I., Vila, Gayana, 1, 100-113, (2006)

5. S. Kelly-Richards, N. Silber-Coats, A. Crootof, D. Tecklin, C. Bauer, Energy Policy, 101, 251-264, (2017)

6. P. Kemp, River Research and Applications, 32(10), 2116-2124, (2016)

7. E. Latrubesse, E. Arima, T. Dunne, E. Park, V. Baker, F. d'Horta, C. Ribas, Nature, 546(7658), 363-369, (2017).

8. O., Link, E., Habit, Reviews in Environmental Science and BioTechnology, 14(1), 921, (2015)

9. Ministry of Energy, by C. Santana, M. Falvey, M. Ibarra, M. García, Renewable energies in Chile: wind, solar and hydroelectric potential from Arica to Chiloé, $1^{\text {st }}$ edition, (2015).

10. N. Myers, R. Mittermeier, C. Mittermeier, G. Fonseca, J. Kent, Nature, 403(6772), 853-858, (2000)

11. M. Noatch, C. Suski, Environment Reviewers Journal, 20, 71-82, (2012)

12. M. Noonan, J. Grant, C. Jackson, Fish and Fisheries, 13(4), 450-464, (2012)

13. Y. Zhou, M., Hejazi, S., Smith, J., Edmond, H., Li, L., Clarke, A., Thomson, Energy and Environmental Science, 8(9), 2622-2633, (2015) 